EGU21-5080, updated on 17 Jan 2022

https://doi.org/10.5194/egusphere-egu21-5080

EGU General Assembly 2021

(c) Author(s) 2022. This work is distributed under

the Creative Commons Attribution 4.0 License.

\title{
Controlled source electromagnetic measurements offshore the Maltese Islands: Implications for offshore freshened groundwater in a carbonate shelf
}

Amir Haroon ${ }^{1}$, Aaron Micallef ${ }^{2}$, Zahra Faghih ${ }^{1}$, Marion Jegen ${ }^{1}$, Katrin Schwalenberg ${ }^{3}$, Jens Karstens ${ }^{1}$, Christian Berndt ${ }^{1}$, Xavier Garcia ${ }^{4}$, Michel Kuehn ${ }^{1}$, Enzo Rizzo ${ }^{5}$, Nicoletta Chiara Fusi ${ }^{6}$, Chibuzo Valeria Ahaneku' ${ }^{2}$, Lorenzo Petronio ${ }^{7}$, and Bradley A. Weymer ${ }^{1}$

${ }^{1}$ Helmholtz Centre for Ocean Research GEOMAR Kiel

${ }^{2}$ Marine Geology \& Seafloor Surveying, Department of Geosciences, University of Malta

${ }^{3}$ Federal Institute for Geosciences and Natural Resources (BGR)

${ }^{4}$ Institute of Marine Science, CSIC, Barcelona

${ }^{5}$ Dipartimento di Fisica e Scienze della Terra, University of Ferrara

${ }^{6}$ Earth and Environmental Sciences Department, University of Milano-Bicocca

${ }^{7}$ Istituto Nazionale di Oceanografia e di Geofisica Sperimentale (OGS)

Carbonate lithologies host considerable quantities of the Earth's freshwater resources and partially supply a significant amount of the global population with drinkable water. Although they comprise substantial amounts of the coastlines, it is not known if these carbonate lithologies can sustain freshened groundwater offshore, and if this can help meet future water demands in coastal regions. To date, predicting volumes of freshened groundwater within marine carbonates has been challenging. Here, we integrate controlled source electromagnetic profiles with seismic reflection and core log data to derive a lithological model for the eastern carbonate margin of the Maltese Islands, one of the most water-starved countries in the world. Electrical resistivity models are used to guide lithological inference where seismic data provide limited information due to the superimposed seafloor multiple. We show that resistivity values within the Upper Coralline and Globigerina Limestone formations exceed the measured resistivity of seawater-saturated core log samples by at least a factor of four. This could be indicative of offshore freshened groundwater that occupies the pore space of the low permeability limestone along the eastern Maltese shelf. To validate this observation without further ground-truthing data, we use extensive forward modelling to show that a similar resistivity footprint can be achieved by localized interbedded lowporosity or highly cemented units. However, the spatial extent of such units across the entire eastern Maltese margin is geologically improbable. This points to the occurrence of offshore freshened groundwater that was likely emplaced during the last sea-level lowstand. 